\title{
Study on operation strategy of dragon boat race from the perspective of sports industry
}

\author{
Hong-chun $\mathrm{Jia}^{1}$, Song-bo $\mathrm{He}^{{ }^{*}}$, Xiang-dong Ding ${ }^{2}$ \\ ${ }^{1}$ Beihua University ,Jilin, China \\ ${ }^{2}$ Beihua University, College of physical education, Longteng innovation and entrepreneurship education \\ base \\ *Corresponding author
}

Keywords: Dragon Boat race, Operation strategy.

\begin{abstract}
Dragon Boat race is an important folk traditional sports in China. It is a sports project which combines Chinese traditional culture, history and sports. The Dragon Boat Race at the national and local government macro-control, based on market mechanism, the competition of rational and effective allocation of resources, in order to improve the competitive level of the dragon boat and create economic benefits, and gradually form a national organic combination with social structure, help the development of the sports industry.
\end{abstract}

\section{Introduction}

In 2002, the dragon boat race became a national sports convention, where dragon boat racing was officially added to the national games. In 2004, the State Sports General Administration and the China Dragon Boat Association jointly launched the Dragon Boat month campaign. This is the landmark beginning of the dragon boat movement which has been vigorously popularized throughout the country. In 2012, the CCTV sports channel held a live broadcast of the dragon boat race for the first time. This is a milestone in the market operation of China's Dragon Boat movement.

\section{Problems existing in Dragon Boat Race Market}

The Dragon Boat Race market value remains to be excavated

The market value of dragon boat race is directly or indirectly related to the quality of competition, and the effect of market development is closely related to the brand, level and development of the event. The more complete competition system, the higher competition intensity and the stronger ornamental, the development potential and development value of Dragon Boat Race market will be greater. Therefore, the Dragon Boat Race market forms a competition system with high level of competition and good brand effect, which is a must for the development of the Dragon Boat Race market.

The Dragon Boat Race funding sources of tension

Most of the events in China are sponsored by the government and enterprises, and very few events are responsible for their profits and losses. Under the market economy function, let the match according to own characteristic, conformity each kind of resources, will consummate the market development pattern. In order to solve the key problems facing the dragon boat races in the development process of the shortage of funds through the market this invisible hand, so as to enhance the economic value of the dragon boat races, to improve the quality of the event, the real integration of market mechanism. 


\section{China dragon boat race, operation, development, countermeasure}

\section{Change the government functions, reform the dragon boat race management system}

The management methods of competition are changed from the simple government administration to the combination of policy and economic means management, and the management style of enterprises is introduced. Jointly run by the state and society, the event will provide a relatively free and easy market environment for the Dragon Boat Race market, so that it can operate in accordance with the laws of the market economy. The management system of dragon boat racing events should be changed from decentralized management system to systematic, integrated and specialized management system, and the functions of sports departments should be clearly defined so as to improve the running efficiency. The government will supervise the operation of the market and integrate and excavate the tangible and intangible resources of the dragon boat races all over the world.

\section{Improve the quality of dragon boat race, build dragon boat race brand}

Improve the Dragon Boat Racing level, scientific and in-depth research on the characteristics of dragon boat race, and accurately grasp the characteristics and essential laws of dragon boat racing skills, innovative training ideas. The integration of perfecting the theory system of dragon boat racing, rowing movement, track depth refinement standard, referees and other special problems, enhance the competitive innovation and standardization of dragon boat sports. Study on the training of dragon boat racing to increase investment in scientific research, improve the technology content of training, to maintain the traditional characteristics of Chinese Dragon Boat Festival, formed with the characteristics of Chinese tactical system, promote the level of Dragon Boat Sports faster to improve better.

\section{Broaden funding channels}

At present, most of China's Dragon Boat Race relies on government support, but it is very difficult to rely solely on the development of the event itself. Therefore, only the rational use of sponsorship, this effective means to promote market development is the most effective way. On the one hand, the organizers of the dragon boat race should strengthen exchanges and communication with sponsors and establish long-term and stable cooperative relations. On the other hand, we should broaden the sources of sponsorship and select influential and competitive enterprises in various fields. Sponsors can give sponsors more rights to motivate sponsors. Can the dragon boat launch ceremony, cultural performances, 100 boat patrol the river, dotting the activities such as developing separately or resources in return given the right to host the sponsors, through a variety of activities to make the Dragon Boat Sports Resources and enterprise brand combination, double win to achieve economic and social benefits.

\section{Make good use of the TV relay rights of dragon boat races}

We will continuously tap the market value of the intangible assets of television rights, and plan to develop and make reasonable pricing. Carrying on multi-channel sale to the broadcast rights of the event, impel each television station to form the competition mechanism, and carry on the free competition, must continue to attract the media organization to the Dragon Boat broadcast market direct intervention. At the same time, the market development platform is built in the form of resource exchange, and new media mode is introduced to construct a three-dimensional reporting model.

\section{Acknowledgements}

This paper is a research project of Beihua University students' innovation project, horizontal topic: Dragon Boat land training equipment (NO:201602014).

\section{References}

[1] Yu. Economic analysis of sports intangible assets and China's management strategies [J]. Shandong sports science and technology, 2004, 26 (3):6-11 
[2] Li, Fu re, Li Yiqun. China's sports intangible assets and their development [J]. China Sports Science and technology, 2006 (42) (4)

[3] bell, Tianlong. Introduction to sports economics, [M]., Second Edition. Shanghai: Fudan University press, 2015.67-69

[4] Jian Bo, Qi Jing. Study on the Countermeasures of the development of intangible assets of dragon boat race [J]. Neijiang science and technology, 2008,29 (3): 17-18

[5] Wang Dali. Development and countermeasure analysis of Dragon Boat Sports [J]. sports science and Technology Bulletin, 2013, 21 (8): 23-24

[6] Xu Feng. SWOT analysis and countermeasure research on dragon boat project in Universities [J]. Journal of Huaihai Institute of Techology, 2013,11 (7): 115-118 